\title{
Developing and Testing Gluten-Free Spaghetti using Quinoa
}

\author{
Cindy Caratini ${ }^{1} \&$ Kurt A. Rosentrater ${ }^{1}$ \\ ${ }^{1}$ Department of Agricultural and Biosystems Engineering, and Department of Food Science and Human \\ Nutrition, Iowa State University, Ames, Iowa, USA \\ Correspondence: Kurt A. Rosentrater, Iowa State University, 3327 Elings Hall, Ames, Iowa, 50011, USA. E-mail: \\ karosent@iastate.edu
}

Received: May 23, 2019

Accepted: June 13, 2019 Online Published: July 15, 2019

doi:10.5539/jfr.v8n5p20

URL: https://doi.org/10.5539/jfr.v8n5p20

\begin{abstract}
The goal of this study was to make quinoa pasta only with flour and water using extrusion processing and to compare quinoa spaghetti with commercial spaghetti from Barilla containing gluten thanks to physico-chemical tests. First, using a KitchenAid, several tests were carried out in order to find the recipe with a suitable proportion of water and quinoa flour. After the moisture content has been found, three formulations with the same moisture content (38\%) were selected using several percentage of pre-gelatinization $(20 \%, 30 \%$ and $40 \%)$ in order to compare the influence of level of pre-gelatinization on dough properties. The pre-gelatinization was in order to improve the texture and the appearance of pasta because with $38 \%$ of moisture content without pre-gelatinization, pasta were too breakable and sticky. However, as regarding results on physico-chemical properties, pre-gelatinization had increased the percentage of cooking loss and the water activity. Moreover, the pre-gelatinization did not have an impact on moisture content, unit density, cooking time and the texture. Concerning the color, the pre-gelatinization had improved the lightness only for $30 \%$ of pre-gelatinization. The main problem with the pre-gelatinization was an excessive starch swelling which caused damage, an irreversible disruption of the protein-starch network. Moreover, the optimal formulation (30\%) used to produce quinoa pasta with extruder, did not have good results. According to sensory analysis, the major problem with quinoa pasta was due to the texture, which was too breakable, with a lack of firmness, as well as the color of quinoa pasta.
\end{abstract}

Keywords: spaghetti, quinoa, gluten-free, extrusion

\section{Introduction}

For many years, cereal grains have been used by humans. The processing of grain gives cereal products rich in starch. The first cereal grains are wheat, rice and maize (Belton and Taylor, 2002). Cereal grains have a nutritional value because provide an important source for nutrients such as a high amounts of protein. These are also important for health. Indeed, several studies have shown that the use of whole grains allow for a reduction in the risk of several diseases such as cancer, diabetes, obesity, cardiovascular disease (Slavin, 2004). Nowadays, cereals become a common food. Indeed, the FAO (Food and Agriculture Organization of the United Nations) reported that in 2015-2016, world cereal utilization is forecast at 2525 million tonnes while cereal utilization was 2050 million tonnes in 2006 (FAO, 2015). Wheat is one of the most used cereals, which owns significant bread-making properties compared to other cereals but wheat contains gluten.

Gluten is composed by two main proteins which give the dough viscoelastic properties: gliadin, determines the viscosity properties and glutenin which responsible for elasticity (Arendt and Dal Bello, 2009). Gluten is present in many products such as bread, baked products, and pasta, and many other products with wheat flour. Gluten is also found in foods that contain barley, rye and oats. Some people can become intolerant or may become sensitive to gluten. This may be due to an intolerance, or due to Celiac disease, which has been defined by inflammation small intestine. Celiac disease is an autoimmune disorder. Or perhaps it can be due to gut microflora. According to Arendt and Dal Bello, 2009, $1 \%$ of the population in the worldwide is affected by celiac disease and according to the FDA 3 million persons in the United States have this disease (FDA, 2015). In the stores, there are a few choices of gluten-free products and this gluten-free products lack of taste compared to gluten food (Atwell and Engleson, 2008). However, there is an increased demand of gluten-free products. Indeed, more and more people would like to follow gluten-free diets because they are not only gluten intolerant, but a member of their family may suffer from Celiac disease. This tendency was illustrated by a survey about food behavior and expectations in the USA (Atwell and Engleson, 2008). Moreover, this disease occurs at any age and 
treatment is a lifelong strict gluten-free diet (Atwell and Engleson, 2008). People affected by Celiac Disease must avoid eat dietary staples that is why it is a challenge to find alternative products. Industries become aware of requirement to develop gluten-free products. According to the FDA (Food \& Drug Administration), a product is defined "gluten-free" if it contains less than $20 \mathrm{ppm}$ of gluten in food (for example $20 \mathrm{mg} / \mathrm{kg}$ ) (FDA, 2015).

Quinoa (Chenopodium quinoa) can be an interesting alternative. The word "Quinoa" named "mother grain" in Inca, is derived from the Spanish (Belton and Taylor, 2002). Quinoa is a resistant plant, adapted to high temperature (Jancurova et al, 2009) (Abugoch, 2009) and it is considered as a pseudo cereal from the Andean region of South America (Belton and Taylor, 2002). Quinoa production has been growing during the last several years. The majority of quinoa is cultivated in South America. However, quinoa cultivation is spreading significantly in other countries such as France (for example in Anjou), England, Sweden, Denmark, Holland and Italy (FAO, 2013). It contains a high percentage of protein (13\%- 14\%) (Chen et al, 2015), similar to that of wheat, 15.4\% (Abugoch, 2009). That is why quinoa can replace meat (Sanchez, 2012). Moreover, Quinoa provides a large source of vitamin especially in the vitamins E and B (Belton and Taylor, 2002), significant amount of fibers and contains a high value in amino acid (lysine and histidine) compared to conventional cereals (Abugoch, 2009). It is also rich in micronutrients such as iron and magnesium (Chen et al, 2015). That is why quinoa is recommended for health because has a high nutritional benefit and does not contain gluten (Abugoch, 2009). That could be a convenience for people suffering from celiac disease. Quinoa can be consumed in several ways either raw in salad or cooked. A negative side is that quinoa contains saponins, which entails a bitter taste to food products. Consequently, it is necessary to wash quinoa grains before use in order to reduce this bitterness (Belton and Taylor, 2002) (Abugoch, 2009). However, it is important to note potential of quinoa for a good diet and for health thanks to a high nutritional composition.

Pasta is a common product. According to Mastromatteo et al., 2011, pasta is one of the most consumed foods in the world. Italy is the biggest pasta consumers worldwide, with $25.3 \mathrm{~kg}$ pasta consumption per person in 2013 (UN.A.F.P.A, 2013). The term "pasta" includes long products such as spaghetti, capellini, short pasta such as fusilli, penne ,and fresh pasta. Pasta is made from durum wheat (Hoseney, 1994). Because of its hardness, durum wheat can't be consumed directly. It must be transformed into semolina, used primarily in pasta production (Hoseney, 1994). Pasta has many advantages as a food, as it is an economic product to produce, purchase, and pasta cooks easily. Their yellowness is a significant factor for consumers. The degradation of carotenoid pigments is responsible for the color (Mirhosseini et al., 2015).

Recent studies have focused on the production of gluten-free spaghetti, but there are few that use quinoa for pasta production (Schoenlechner et al., 2010). Among studies on gluten-free products, use of dairy products or hydrocolloids is essential to improve the texture of gluten-free foods (Larroza et al., 2015). Thus, the main objectives of this research were to make gluten-free pasta using only quinoa and water, and then to analyze their quality. First, using a KitchenAid, several tests were carried out in order to optimize the recipe with a suitable proportion of water and quinoa flour. After the moisture content was optimized, three formulations were selected using several percentages of pre-gelatinization in order to compare the influence of level of pre-gelatinization on dough properties. Afterwards, the optimal formulation was used to produce quinoa pasta with an extruder to evaluate effect of extrusion on quinoa pasta. The objective was to compare quinoa pasta with commercial spaghetti (containing wheat) according to physico-chemical properties. Subsequently, sensorial analysis and consumer acceptance testing were performed on control spaghetti, spaghetti with $30 \%$ of pre-gelatinization, extruded optimized formulation, and commercial spaghetti.

\section{Materials and Methods}

\subsection{Raw Material}

Quinoa (Chenopodium quinoa) seeds were supplied by Angelina's Gourmet (Waukegan, IL, USA, reference lot L763352). The seeds were stored in a plastic $11.3 \mathrm{~kg}$ bag.

Grains were milled into particles of diameter $0.7 \mathrm{~mm}$. Quinoa flour was obtained using a grinding machine (Cyclone Sample Mill, model 3010-030, UDY CORPORATION, Fort Collins, CO, USA).

\subsection{Chemical Analyses}

Chemical analyses were carried out on quinoa flour by Servi-Tech Laboratories (Hastings, NE, USA), and included crude protein, crude fiber, ash and fat on $100 \%$ dry matter quinoa flour. 


\subsection{Pasta Formulation}

\subsubsection{Dough Preparation}

Spaghetti formulations are shown in Table 1. Flour and water were only ingredients in the spaghetti preparation. In order to prepare pre-gelatinized starch, different percentage weight fraction of flour $(20 \%, 30 \%$ and $40 \%)$ presented in Table 1 was incorporated in the warm water for each formulation and the mix was heated to $69.5^{\circ} \mathrm{C}$ in a hot water bath (Model 2876, Marietta, OH, USA) during $40 \mathrm{~min}$. Afterwards, the pre-gelatinized starch, cooled at about $40^{\circ} \mathrm{C}$ in an ice water bath, was added to the rest of flour to prepare a homogenous doughs using a domestic blender (KitchenAid 4.5 quart (4.3L), tilt-head stand mixer, Model Classic Plus KSM75WH, St. Joseph, MI, USA). Flour and water were mixed at speed 1 for $6 \mathrm{~min}$ to $8 \mathrm{~min}$ according to percentage weight fraction of gelatinization reported in Table 1. Then, kneading was carried out for $20 \mathrm{~min}$ in total. A control sample without pre-gelatinization was carried out named "control spaghetti".

Table 1. Formulations used for quinoa spaghetti trials. All values in $\%(\mathrm{w} / \mathrm{w})$

\begin{tabular}{l|l|lll}
\hline & Control & \multicolumn{3}{|c}{ Treatments $(\%, w / w)$} \\
\hline Ingredients & & $20 \%$ & $30 \%$ & $40 \%$ \\
\hline Quinoa Flour, Pre-gelatinized & 0 & 12.4 & 18.6 & 24.8 \\
Quinoa Flour, non-Pre-gelatinized & 62 & 49.6 & 43.4 & 37.2 \\
Water & 38 & 38 & 38 & 38 \\
\hline Total & 100 & 100 & 100 & 100 \\
\hline
\end{tabular}

\subsubsection{Spaghetti Preparation with KitchenAid}

After pasta dough preparation, spaghetti was produced using the same KitchenAid previously discussed above, with the pasta press equipped with a disc for spaghetti (reference W10236413B with die diameter of $1.65 \mathrm{~mm}$ ). All pasta formulations were produced in triplicate. Finally, pasta was dried overnight at ambient air for $24 \mathrm{~h}$.

\subsubsection{Spaghetti Preparation with an Extruder}

According to physico-chemical results, the best dough formulation used with KitchenAid (30\% of pre-gelatinization) was chosen for extruder. After pasta dough preparation of this formulation with the KitchenAid, quinoa spaghetti was prepared using an extruder (model 2003, C.W. Brabender Instruments, South Hackensack, NJ, USA). The extruder had $19.18 \mathrm{~mm}$ inner diameter with a screw compression ratio of 1:1 (the depth of the screw at the feed was the same as at the die). The die has a diameter of $1.40 \mathrm{~mm}$. The screw (model 05-00-035, Brabender) had $381 \mathrm{~mm}$ of length, $19.05 \mathrm{~mm}$ outside diameter, a screw length-to-diameter ration of 20:1, a $19.05 \mathrm{~mm}$ uniform pitch, an $11.43 \mathrm{~mm}$ initial screw root diameter and a $3.81 \mathrm{~mm}$ initial screw feed depth. This is in conjunction with a rheometer drive control system (model PL 2000, Plasti-Corder, Brabender). The extruder screw speed was maintained at $50 \mathrm{rpm}$ and the temperature was controlled and maintained at $20^{\circ} \mathrm{C}$ (ambient condition) during extrusion. Dough was manually inserted into the extruder in small quantity to avoid overloading the extruder.

\subsection{Cooking Quality}

\subsubsection{Color Evaluation}

Color of uncooked quinoa spaghetti was determined instrumentally according to the CIE 1976 using a Minolta CR 410 Chroma meter (Konica Minolta Optics, Inc. Chromameter, Ramsey, NJ, USA). The petri dish where samples were entirely filled in order to avoid interference with the light. $\mathrm{L}^{*}$ for the lightness ranging from 0 to 100 (darkness/ brightness), $\mathrm{a}^{*}$ (greenness/ redness) and $\mathrm{b}^{*}$ (blueness/ yellowness) were read directly. If there was difference between two products, this difference could be evaluated by calculating $\Delta \mathrm{E}$ (Mokrzycki and Tatol, 2011):

$$
\Delta \mathrm{E}=\sqrt{(\Delta \mathrm{L} *)^{2}+(\Delta \mathrm{a} *)^{2}+(\Delta \mathrm{b} *)^{2}}
$$

\subsubsection{Optimal Cooking Time and Cooking Loss}

The optimal cooking time (OCT) was evaluated using the AACC official method 66-50 (AACC, 2000). 10g of pasta were cut into $5 \mathrm{~cm}$ and were added to beaker containing $300 \mathrm{~mL}$ boiling distilled water. Every $30 \mathrm{sec}$, one pasta was taken and pressed between two transparent glass slides. The optimal cooking time corresponded to the disappearance of the core of spaghetti.

Cooking loss was determined using the AACC method 66-50 (AACC, 2000). 10g of pasta were added to a pre-weighed beaker of $500 \mathrm{~mL}$ containing $300 \mathrm{~mL}$ boiling distilled water. After the optimal cooking time, 
cooking water was evaporated to dryness in air oven at $100^{\circ} \mathrm{C}$ during approximately 48 hours. Afterwards, the beaker was weighed and the percentage of cooking loss was calculated by the following equation:

$$
\% \text { of cooking loss }=\frac{(\text { beaker weight after cooking }(g)-\text { preweight beaker }(g)) \times 100}{\text { original pasta weight }(g)}
$$

\subsubsection{Water Absorption}

Water absorption capacity (WAC) was determined using the AACC method 66-50 (AACC, 2000). $10 \mathrm{~g}$ of pasta were added to beaker containing $300 \mathrm{~mL}$ boiling distilled water. After the optimal cooking time, pasta were dried, rinsed in cold water and weighted. Water absorption $(\%)$ was determined as:

$$
\% W A C=\frac{\text { weight of cooked pasta }(g)-\text { weight of dried pasta }(g)}{\text { weight of dried pasta }(g)} \times 100
$$

\subsection{Texture Properties of Uncooked Pasta}

The texture was evaluated on uncooked pasta using a three point bending test. The three-point bend test measured the necessary force to break the pasta sample. Spaghetti was submitted to this force after placing it between two supports. The probe movement caused deformation of the pasta sample before it broke. The variable recorded was maximum peak height. The texture analyzer used was model TA-XT2 (Texture Technologies, Scarsdale, NY). The three-point bending fixture was model TA-92N (Texture Technologies, Scarsdale, NY). Prior to use, the texture analyzer was calibrated with a load cell of $5 \mathrm{~kg}$. The gap between supports was measured to be about $14 \mathrm{~mm}$. Afterwards, the probe descended for a distance of $5 \mathrm{~mm}$, with speed at $1.00 \mathrm{~mm} / \mathrm{s}$, stopped, and returned to the start position.

\subsection{Water Activity}

Water activity was measured at $25^{\circ} \mathrm{C}$ using a calibrated water activity meter (AquaLab, series 3TE, model 0800753, Decagon Devices, Inc., Pullman, WA, USA). All analyses were carried out in triplicate on each pasta.

\subsection{Moisture Content}

Moisture content (\%, wet basis, w.b.) was determined according to the AACC method 44-19 (AACC, 2000). Pasta were mixed and $2 \mathrm{~g}$ samples were dried at $135^{\circ} \mathrm{C}$ during 2 hours. Moisture content was calculated as:

$$
\% \text { Moisture and volatile matter }(w . b .)=\frac{\text { loss of moisture }(g) \times 100}{\text { original weight of sample }(g)}
$$

\subsection{Unit Density}

Dried pasta were cut to pieces and weighed on an analytical balance (Explorer Pro, model EP2102C, Ohaus Corporation, Pine Brook, NJ, USA). Then diameter was measured with an electronic Digital Caliper (Model 14-648-17, FB70250, 32599, distributed by Fisher Scientific, 300 Industry Drive, Pittsburgh, PA, USA). The unit density was calculated according to Rosentrater et al (2005) as:

$$
\text { Unit density }\left(\mathrm{kg} / \mathrm{m}^{3}\right)=\frac{\operatorname{mass}(\mathrm{kg})}{\text { volume }\left(\mathrm{m}^{3}\right)}
$$

In order to determine the volume $\left(\mathrm{m}^{3}\right)$, spaghetti were assessed as cylinders.

\subsection{Sensory and Consumer Analyses}

Quality of cooked quinoa pasta was evaluated by sensory analysis. The test was carried out according to the AFNOR norm, in a specific room. The panel was composed of 10 untrained participants. Each panelist was tasted approximately $2 \mathrm{~g}$ of each sample. The pasta products were cooked using the optimal cooking time and were served harm. Then, panelist responded by filling two sheets: one deals with sensory test with 5 items (vision, odor, texture like stickiness, firmness, flavor like aroma, global quality) using a 5-point hedonic scale in order to evaluate the sensorial attributes and the other was consumer test using a 5-point hedonic scale where at 1 $=$ dislike extremely and $5=$ like very much in order to know if consumers will be ready to buy the product. Panelist had read all instructions before to begin the test. Each product had a code of 3 letters and for each product; each panelist had a test sheet corresponding with the same code. For each product, they had to look at the product in first of all and then they had to mark the product on vision descriptors. Then, they had to smell the product and mark it on odor descriptors. Finally, they had to mark the product on taste descriptors. 


\subsection{Statistical Analysis}

The means and standard deviations were determined for physico-chemical properties studied for quinoa spaghetti and for commercial spaghetti using Microsoft Excel v.2013. The commercial spaghetti was from Barilla, and contained wheat. Each analysis was carried out in triplicate. The data were compared by analysis of variance (ANOVA) and Tukey's test using Minitab v.17 in order to find if there were significant differences between the samples, with Type I error rate (alpha) of 0.05 .

\section{Results and Discussion}

Examples of the pasta samples which were produced during this study are shown in Figures 1-6.

\subsection{Chemical Composition}

The chemical composition of quinoa flour is presented in Table 2. Protein is very important for health, especially for immune response and digestibility. Anses (2013) recommends consuming a protein content of $10 \%$ to $27 \%$ of daily amount. Quinoa flour has a higher level of protein (18\%) compared to other cereals. Then, the quinoa flour had a low ash content $(2.6 \%)$.

Table 2. Chemical composition of quinoa flour (100\% dry matter)

\begin{tabular}{ll}
\hline Component & Composition $(\%$, d.b. $)$ \\
\hline Crude protein & 18.0 \\
Crude fiber & 2.3 \\
Ash & 2.6 \\
Fat & 7.2 \\
Other & 69.9 \\
\hline Total & 100 \\
\hline
\end{tabular}

Dietary fibers are not digested in the small intestine. They provide several health benefits for the human, and they are advised for weight loss. The quinoa flour has a low crude fiber content $(2.3 \%)$. It was lower than the fiber content found by Ogungbenle, $2003(9.50 \%)$ which considered quinoa flour as a source of dietary fiber.

\subsection{Color}

The color of spaghetti is important for consumer. Indeed, according to the sensory analysis, color was a decisive criterion for the panelists. The results showed (Table 3) that a reduction in lightness values $\left(\mathrm{L}^{*}\right)$ could be observed with increasing pre-gelatinization levels. The pre-gelatinization improved the lightness until specific level. Indeed, the lightness for control spaghetti was $44.34 \pm 0.42$ (Table 3) whereas for $30 \%$ of pre-gelatinization starch, the lightness was $41.12 \pm 0.09$ and $40.18 \pm 0.50$ for $40 \%$ of pre-gelatinization starch (Table 3). No significant difference ( $\mathrm{P}>0.05$ ) was found for the lightness between $30 \%$ of pre-gelatinization starch and commercial spaghetti. Increasing of darkness was probably due to the Maillard reaction (Bustos et al., 2015). Indeed, the pre-gelatinization samples containing water and flour were heated until $69.5^{\circ} \mathrm{C}$, sugars have been reduced, resulting decreasing of lightness.

Concerning extruded sample, the lightness decreased compared to sample with KitchenAid (Table 3). A possible explanation is, as diameter die of extruder was smaller than diameter die of KitchenAid, dough was thinner. Consequently, spaghetti dried faster. Moreover, the extruder screw speed was too fast, dough was very sticky, not like KitchenAid. The speed of the screw could have an impact of final spaghetti.

Regarding $\mathrm{a}^{*}$ values, there were significant differences $(\mathrm{P}<0.05)$ between all samples but the color was rather green (Table 3). A low red value is appropriate for pasta products (Guine and Correia, 2014). Then, $b^{*}$ value were most important for cooking quality because it determines the yellow color of pasta (Guine and Correia, 2014). Significant differences ( $P<0.05$ ) were found between all samples, except those with $20 \%$ and $30 \%$ of pre-gelatinization. As there were significant differences between control spaghetti and pre-gelatinization sample, the pre-gelatinization had an effect on the $b^{*}$ value, probably due to the Maillard reaction. These samples had a negative $b$ value whereas commercial spaghetti had a positive $b$ value, being a desirable color for pasta product. The enzyme lipoxygenase may be responsible for the yellow color pasta. There were carotenoid pigments in the pasta. The enzyme lipoxygenase bleaches the yellow carotenoid pigments by oxidation during pasta processing (Belton and Taylor, 2002). 
Table 3. Color results for quinoa spaghetti trials (KitchenAid and extruder) and commercial spaghetti. Data are presented as means \pm standard deviations

\begin{tabular}{|c|c|c|c|}
\hline & $\mathrm{L}^{*}$ & $a^{*}$ & $\mathrm{~b}^{*}$ \\
\hline Control spaghetti $*$ & $44.34^{\mathrm{a}} \pm 0.42$ & $-0.3^{\mathrm{abc}} \pm 0.02$ & $-4.28^{a} \pm 0.19$ \\
\hline $20 \% * *$ & $42.93^{\mathrm{b}} \pm 0.25$ & $-0.5^{\mathrm{c}} \pm 0.02$ & $-3.73^{\mathrm{ab}} \pm 0.09$ \\
\hline $30 \% * *$ & $41.12^{\text {cd }} \pm 0.09$ & $-0.2^{\mathrm{a}} \pm 0.01$ & $-3.36^{b c} \pm 0.16$ \\
\hline $40 \% * *$ & $40.18^{d} \pm 0.50$ & $-0.4^{\mathrm{bc}} \pm 0.04$ & $-2.88^{\mathrm{c}} \pm 0.13$ \\
\hline Extruder spaghetti & $33.20^{\mathrm{e}} \pm 0.62$ & $0.3^{\mathrm{d}} \pm 0.01$ & $-0.04^{\mathrm{d}} \pm 0.37$ \\
\hline Commercial spaghetti & $41.70^{\mathrm{c}} \pm 0.29$ & $-4.3^{\mathrm{f}} \pm 0.09$ & $16.90^{\mathrm{e}} \pm 0.22$ \\
\hline
\end{tabular}

\subsection{Unit Density}

No significant difference $(\mathrm{P}>0.05)$ was found for unit density between commercial spaghetti and sample with $30 \%$ of pre-gelatinization starch (Table 4). The unit density for commercial spaghetti was $1305.75 \pm 42.49 \mathrm{~kg} / \mathrm{m}^{3}$. Unit density decreased slightly with pre-gelatinization levels. According to Bustos et al., 2015, a product with lower density, will occupy a greater volume because of water absorption by starch. There was a relationship between increasing volume pasta and the density of pasta.

Concerning extruded sample, no significant difference $(\mathrm{P}>0.05)$ was found between extruded sample and KitchenAid sample and commercial spaghetti (Table 4). The extruder did not have an impact on unit density of quinoa spaghetti.

\subsection{Cooking Time}

According to Fiorda et al., 2013, the optimal cooking time should increase with increasing percent of pre-gelatinization starch. This fact was showed in the result table 4 . The optimal cooking time was slightly increased with pre-gelatinization. The possible explanation could be due to the presence of high level of fibers and proteins in the quinoa flour which absorbed more cooking water, consequently in the case of pre-gelatinization, the water would be less available for quinoa starch gelatinization, which entails a longer cooking time (Fiorda et al., 2013). Nevertheless, according statistic test, no significant difference (P > 0.05) was found between several quinoa pasta samples for optimal cooking time (Table 4).

However, the optimal cooking time for all gluten-free pasta was lower (around $4 \mathrm{~min}$ ) than commercial pasta $(6.43 \pm 0.51 \mathrm{~min})$ containing gluten (Table 4). In fact, commercial spaghetti was characterized by an important gluten network, which established chemical bonds between protein and starch. Consequently, a protective layer is formed on the surface of spaghetti. Thus, the water needs more time to reach the spaghetti matrix, mainly the spaghetti center. That is why the optimal cooking time is longer with commercial spaghetti containing gluten than gluten-free pasta (Chillo et al., 2007 cited by Padalino et al., 2013).

Concerning extruded sample, no significant difference $(\mathrm{P}>0.05)$ was found between extruded sample and KitchenAid sample (Table 4). The different ways to produce pasta did not have an impact on cooking time.

\subsection{Moisture Content}

Moisture content is an indicator of the amount of water present in the food product. Moisture content can be related to the color of the pasta. The moisture content level had to be of about $12.5 \%$ (not more than 13\%) after drying in order to avoid contamination by microorganisms (Bustos et al., 2015). Drying is very important step because it determines quality pasta products. Regarding results (Table 4), all pasta samples had moisture content levels lower than $12.5 \%$. All pastas had good quality concerning moisture content level.

No significant differences $(\mathrm{P}>0.05)$ was found between control spaghetti and pre-gelatinized samples. All pre-gelatinization samples had a moisture level of about $11 \%$ (Table 4). Consequently, the pre-gelatinization did not have an impact on moisture content. Thus, the percentage of water in the product corresponding to the available water and bound water was the same for the several samples. However, there were significant differences $(P<0.05)$ between quinoa spaghetti and commercial spaghetti. These differences were probably caused of different processing used for drying pasta, because drying affects the percentage of moisture content.

Regarding the extruded sample, moisture content was higher than the other formulations $(12.18 \% \pm 0.15$, Table 4). This fact was probably due to the different percentage of humidity during drying of the pasta, because pasta was not dried the same day. 


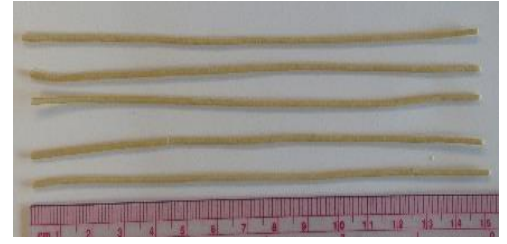

Figure1. Quinoa spaghetti with $20 \%$ of starch pre-gelatinization.

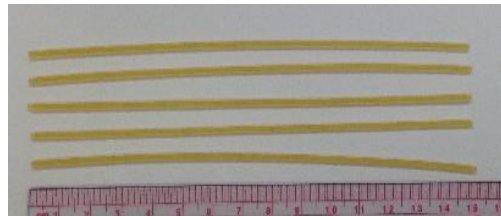

Figure 4. Commercial spaghetti.

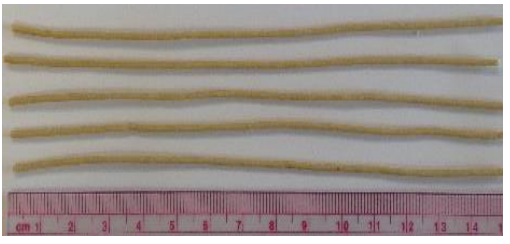

Figure 2. Quinoa spaghetti with $30 \%$ of starch pre-gelatinization.

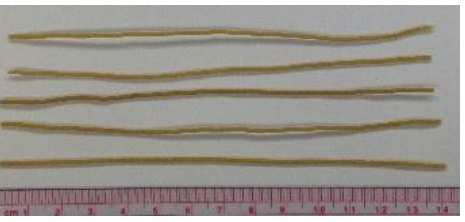

Figure 5. Extruder sample: quinoa spaghetti with $30 \%$ of pre-gelatinization.

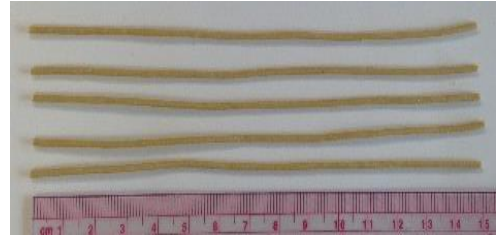

Figure 3. Quinoa spaghetti with $40 \%$ of starch pre-gelatinization.

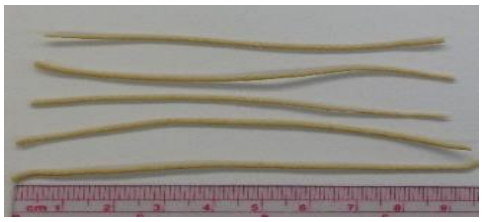

Figure 6. Control quinoa spaghetti (without starch pre-gelatinization).

* Scale gradations shown in the figures are $\mathrm{cm}$.

\subsection{Water Activity}

Water activity is the measure of free water available in the product. Water activity has an impact on food storage, and it characterizes the shelf life of a product. The higher the water activity, the higher the product will be contaminated by microorganisms such as molds, bacteria.

The results (Table 4) showed that water activity increased slightly with increasing pre-gelatinization levels. Thus, there was significantly $(\mathrm{P}<0.05)$ more available water in the pre-gelatinized sample than control spaghetti but the results were almost similar. This was consistent because when starch is heated with excess water, an irreversible phenomena occurs named gelatinization. Hence, starch granules swell and hydrogen bonds brake. At the same time, viscosity increases, which involves gel formation during the cooling corresponding to the starch retrogradation. This gel is able to absorb important water capacity but this water is equivalent to available water. That was the reason why, in this study, the water activity was higher in the case of pre-gelatinization.

No significant difference $(\mathrm{P}>0.05)$ was found between extruded sample and pre-gelatinization samples (Table 4). This fact was probably due to the difference temperature between samples during the drying and different weather condition like humidity could be affected the water activity.

\subsection{Cooking Loss}

The quantity of solids, which stays into water during cooking, is also an important factor for quality pasta products. Hummel, 1996 and Kruger et al., 1996 (cited by Fiorda et al., 2013) evaluated that pasta products with $6 \%$ of cooking loss were very good; pasta products with $8 \%$ were regular; and $10 \%$ was very bad. Tam et al., 2004 (cited by Padalino et al., 2013) reported that a spaghetti with a strong network starch, especially due to starch gelatinization, can reduce the percentage of cooking loss. Moreover, gelatinized starch would improve pasta integrity (Cunin et al., 1995) because the protein starch matrix is more consolidated during boiling. In this way, starch would be resistant.

In this study, the use of pre-gelatinization in order to improve the starch network did not have the same effect. Indeed, the pre-gelatinization had increased the percentage of cooking loss of $27 \%$ for $20 \%$ of pre-gelatinization starch, $44 \%$ for $30 \%$ of pre-gelatinization starch and $55 \%$ for $40 \%$ of pre-gelatinization starch (Table 4). Theses samples were considered bad cooking quality according to Hummel, 1996 and Kruger et al., 1996 (cited by Fiorda et al., 2013) given that the percentage of cooking loss was slightly higher than $10 \%$. This increasing of percentage of cooking loss was due to an excessive starch swelling (Delcour et al., 2012). During pre-gelatinization, starch granules were swollen thanks to interaction between flour and water with heat and during the boiling, starch granules were still swollen. Hence, there was a starch network disruption too important which entails a negative effect instead of improve the network structure. Also, increasing of cooking loss could be caused by fibers, which use a higher water quantity. Thus, there would be less water available for the starch swelling (Tudorica et al., 2002). On the contrary, the control spaghetti showed good cooking quality regarding the percentage of cooking loss $(7.86 \pm 0.42 \%$, Table 4$)$. This sample was considered regular. 
Commercial spaghetti was evaluated like very good pasta (5.95 $\pm 0.66 \%$, Table 4). Regarding the percentage of cooking loss, there were significant differences $(\mathrm{P}<0.05)$ between commercial spaghetti and quinoa pasta. Moreover, protein transformation has to occur before starch gelatinization in order to insure a good integrity during cooking (Feillet, 2000). The capacity of pasta to preserve their integrity after cooking is due to the protein capacity to create an insoluble strong network (Delcour et al., 2012). The network is characterized by the ability of the protein to associate each other by disulfide and hydrogen bond and hydrophobic interactions (Feillet, 2000). This network must be able to encapsulate starch granules during gelatinization. Proteins are different between quinoa pasta and commercial spaghetti containing wheat. Indeed, commercial spaghetti is composed of two proteins: gliadins and glutenins, which constitute a gluten network. This strong network is able to prevent loss of solid during cooking. Moreover, quinoa contains less starch (48- 69\% of starch) than commercial spaghetti composed by wheat (65-71\% of starch) (Qian and Kuhn, 1999). The size of starch granules in quinoa are also smaller than in wheat, which could help explain the behavior difference.

Concerning extruded sample, the percentage of cooking loss was to $15.93 \pm 0.55 \%$ (Table 4). This percentage was not acceptable for quality pasta products and that pasta samples were considered as very bad. At the end of extruder, the extrudates were breakable and too sticky, which could explain the higher percentage of cooking loss.

\subsection{Water Absorption}

During drying, denaturalization, polymerization and aggregation of proteins allowed to create a solid film on spaghetti surface (Bustos et al., 2015). During boiling, this film is perturbed by cooking water, which penetrates into the protein matrix (Bustos et al., 2015). Moreover in the other hand, starch granules absorb water and swell (Guine and Correia, 2014). Consequently, the volume of pasta increased. Cooking led to coagulation of proteins. During cooking, Bustos et al., 2015, reported that pasta is considered acceptable if they absorb approximately $150-200 \mathrm{~g}$ of water/ $100 \mathrm{~g}$ pasta. There was no significant difference $(\mathrm{P}>0.05)$ between the several levels of pre-gelatinization. The mean percentage of water absorption was $135 \%$ for the several levels of pre-gelatinization (Table 4). However, there was a difference between control spaghetti and pre-gelatinization sample. Indeed, like those previously cited, commercial spaghetti were able to absorb more water thanks to their strong protein-starch network than quinoa pasta.

The pre-gelatinization had influenced the percentage of water absorption. Indeed, the pre-gelatinization pasta absorbed a higher amount of water, average 32\% more absorbed than without pre-gelatinization (Table 4). According to Bustos et al., 2015, pre-gelatinized pasta were allowed to absorb more water thanks to their disrupted starch network. This fact is more evident in the case of commercial spaghetti with their strong gluten network.

Concerning extruded sample, no significant difference $(\mathrm{P}>0.05)$ was found between pre-gelatinized samples and extruded sample (Table 4). The extruder did not have an impact on percentage of water absorption.

\subsection{Texture Analysis}

The higher the pre-gelatinization level increased, the less force was required for failure. Indeed, the force applied for $20 \%$ of pre-gelatinization starch was $106.72 \pm 10.62 \mathrm{~g}$ whereas for $30 \%$ of pre-gelatinization starch, the force was $85.04 \pm 5.44 \mathrm{~g}$ and $56.92 \pm 11.64 \mathrm{~g}$ for $40 \%$ (Table 4). However, according to the statistic test, there was no significant difference $(\mathrm{P}>0.05)$ between control spaghetti and pre-gelatinized samples. The lower force value was probably due to the disruption of the protein-starch network caused by an excessive starch swelling (Delcour et al., 2012).

The force for commercial spaghetti was $454.47 \pm 4.86 \mathrm{~g}$ (Table 4). There was a significant difference $(\mathrm{P}<0.05)$ with gluten-free pasta. The protein-network is responsible for texture of pasta. A higher protein level can improve texture, firmness, and stickiness (Guine and Correia, 2014). This was the case for commercial spaghetti with their gluten-network stabilized by hydrophobic interactions and hydrogen bonds, which allowed the pasta to have a good texture (Guine and Correia, 2014). Indeed, gluten is composed by two main proteins which give the dough viscoelastic properties: gliadin, determines the viscosity properties and glutenin which responsible for elasticity (Arendt and Dal Bello, 2009). Whereas, in the case of quinoa pasta, gliadin and glutenin are not present and the loss of firmness was probably due to a lack of amylose-protein interactions, as considered by Vignaux et al., 2005 (cited by Agama et al., 2009) as a major factor. Amylose is a macromolecule present in the starch. The level of amylose plays an important role. There is a lower amylose content in the quinoa, 12.2\% (Qian and Kuhn, 1999), than in the wheat, 26.7-28.8\% (Raeker et al., 1998). Amylose is stabilized by strong hydrogen bonds (Bauer et al., 2010). That is the reason why a higher amylose content allows a strong network structure, and thus, pasta with a firm texture. 
The lowest value force was significantly observed for extruded sample $(56.92 \pm 4.86 \mathrm{~g})$. This fact was probably caused by a high screw speed. Pasta was too breakable at the end of the extruder.

\subsection{Sensory Analysis}

Concerning the global appearance (Figure 8), there was significant difference $(\mathrm{P}<0.05)$ between commercial spaghetti and quinoa pasta. No significant difference $(P>0.05)$ was found between the several quinoa pasta samples (Table 6). Panelists were considered that quinoa pasta had the same color value; they did not perceived the significant difference. However, according to the $\Delta \mathrm{E}$ (Mokrzycki and Tatol, 2011) related to the difference between two colors, observers should notice two different colors between control spaghetti and extruded sample $(\Delta \mathrm{E}=11.93)$, commercial spaghetti and all quinoa pasta $(\Delta \mathrm{E}=20)$, KitchenAid sample and extruded sample $(\Delta \mathrm{E}$ $=8.60)$. Moreover, unexperienced observer should notice the difference between control spaghetti and KitchenAid sample $(\Delta \mathrm{E}=3.35)$. Nevertheless, panelists did not perceive the difference. After boiling, the color was not different for perceive difference, probably caused by the enzyme lipoxygenase (Belton and Taylor, 2002) which had the same effect for all quinoa samples. No significant difference $(\mathrm{P}<0.05)$ was found concerning the placement of pasta: separated or aggregated (Figure 7). Thus, quinoa pasta were considered "separated" after cooking, like commercial spaghetti, with a score of 3.00 on 5 (Table 5).

Regarding odor (Figure 8$)$, there were significant difference $(\mathrm{P}<0.05)$ between commercial spaghetti and quinoa pasta. No significant difference $(\mathrm{P}>0.05)$ was found between several quinoa pasta samples. Quinoa pasta had an herbaceous odor with a mean score of 3.00 on 5 (Table 5, Figure 7). However, no significant difference $(\mathrm{P}>0.05)$ was found for the cereal odor for commercial spaghetti and quinoa pasta (Table 5).

Concerning texture (Figure 8), there were significant difference $(\mathrm{P}<0.05)$ between commercial spaghetti and quinoa pasta. No significant difference $(\mathrm{P}>0.05)$ was found between several quinoa pasta samples. However, panelists were attributed similarly value for the firmness between commercial spaghetti (score of $2.90 \pm 1.20$ on 5 , Table 5) and quinoa pasta (mean score of 2.60 on 5, Table 5). Furthermore, commercial spaghetti were considered "elasticated" by panelist with a score of $1.70 \pm 0.95$ on 5 ( 5 were considered breakable). Then, KitchenAid sample had the second score with $2.30 \pm 0.67$ on 5 . Extruder sample was considered as the more breakable pasta (Table 5).

Regarding the taste (Figure 8), there were significant difference $(\mathrm{P}<0.05)$ between commercial spaghetti and quinoa pasta. On the bitter scale, the lower score was obtained by commercial spaghetti ( $1.70 \pm 0.67$ on 5 , Table 5). The higher score was for control spaghetti ( $3.20 \pm 0.92$ on 5, Table 5), considered like the more bitter pasta. This bitter taste was probably caused by saponins, present in the quinoa (Belton and Taylor, 2002).

Finally, concerning global quality, there were significant difference $(\mathrm{P}<0.05)$ between commercial spaghetti and quinoa but no difference $(\mathrm{P}>0.05)$ was found between several quinoa pasta samples. Thus, they were evaluated as having the same quality (Table 5).

Concerning the consumer test (Figure 8), panelists preferred the commercial spaghetti. However, before eat pasta, $70 \%$ of panelists indicated for the KitchenAid sample that they "would probably be ready to consume it" in their daily life. The same percentage was found for the control spaghetti and 50\% of panelists declared that they "would probably be ready to consume" extruded sample. After consumption, the percentage of preference was decreased. Indeed, only $50 \%$ of panelists indicated that they "would probably ready to consume" the KitchenAid sample, $40 \%$ for control spaghetti and extruded sample. This decreasing was mainly due to the bitter taste. Moreover, in general panelists noticed that they were mainly disliked the color of quinoa pasta and the smelt. However, they emphasized that they appreciated the texture of KitchenAid sample.

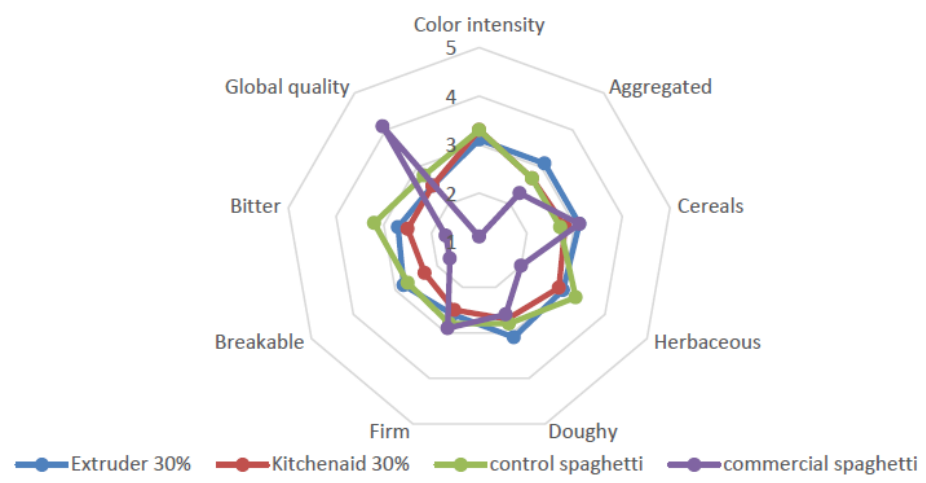

Figure 7. Sensory panel results for quinoa pastas and commercial pasta. 


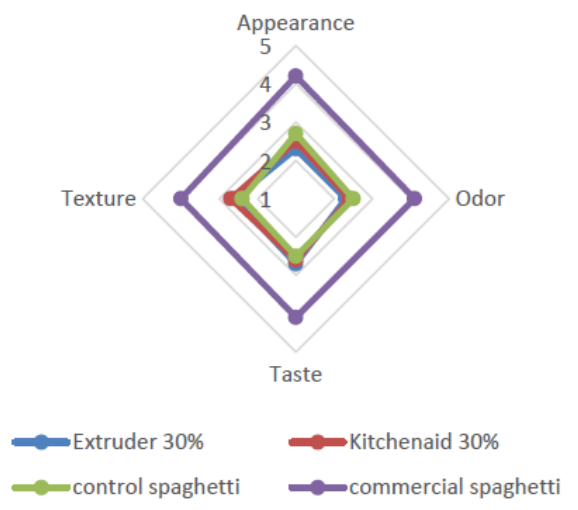

Figure 8. Consumer panel results for quinoa pastas and commercial pasta.

Table 4. Physical property results for quinoa spaghetti trials (KitchenAid and extruder) and commercial spaghetti. Data are presented as means \pm standard deviations

\begin{tabular}{|c|c|c|c|c|c|c|c|}
\hline & Unit density $\left(\mathrm{kg} / \mathrm{m}^{3}\right)$ & Moisture content (\%) & Water activity & Cooking time (min) & Cooking loss (\%) & Water absorption (\%) & Texture $(\mathrm{g})$ \\
\hline Control spaghetti $*$ & $1218.73^{\mathrm{a}} \pm 103.79$ & $11.02^{\mathrm{a}} \pm 0.31$ & $0.54^{\mathrm{ab}} \pm 0.01$ & $3.77^{\mathrm{a}} \pm 0.40$ & $7.86^{\mathrm{a}} \pm 0.42$ & $102.20^{\mathrm{a}} \pm 13.74$ & $112.34^{\mathrm{ab}} \pm 14.41$ \\
\hline $20 \% * *$ & $1163.05^{\mathrm{a}} \pm 54.21$ & $11.42^{\mathrm{a}} \pm 0.10$ & $0.54^{\mathrm{abc}} \pm 0.00$ & $3.77^{\mathrm{a}} \pm 0.40$ & $10.00^{\mathrm{b}} \pm 0.17$ & $134.89^{\mathrm{bc}} \pm 5.50$ & $106.72^{\mathrm{ab}} \pm 10.62$ \\
\hline $30 \% * *$ & $1282.28^{\mathrm{a}} \pm 133.71$ & $11.03^{\mathrm{a}} \pm 0.32$ & $0.57^{\mathrm{de}} \pm 0.00$ & $3.87^{\mathrm{a}} \pm 0.51$ & $11.35^{\mathrm{c}} \pm 0.05$ & $132.92^{\mathrm{bc}} \pm 2.25$ & $93.70^{\mathrm{ab}} \pm 5.44$ \\
\hline $40 \% * *$ & $1130.51^{\mathrm{a}} \pm 15.76$ & $11.42^{\mathrm{a}} \pm 0.10$ & $0.57^{\mathrm{d}} \pm 0.01$ & $4.00^{\mathrm{a}} \pm 0.00$ & $12.15^{\mathrm{c}} \pm 0.35$ & $134.89^{\mathrm{bc}} \pm 5.50$ & $85.04^{\mathrm{bc}} \pm 11.64$ \\
\hline Extruder spaghetti & $1302.74^{\mathrm{a}} \pm 127.30$ & $12.18^{\mathrm{b}} \pm 0.15$ & $0.56^{\mathrm{cde}} \pm 0.01$ & $3.83^{\mathrm{a}} \pm 0.29$ & $15.93^{\mathrm{d}} \pm 0.55$ & $148.61^{\mathrm{bc}} \pm 11.96$ & $56.92^{\mathrm{c}} \pm 4.86$ \\
\hline Commercial spaghetti & $1305.79^{\mathrm{a}} \pm 42.49$ & $9.20^{\mathrm{c}} \pm 0.04$ & $0.55^{\text {bce }} \pm 0.01$ & $6.43^{\mathrm{b}} \pm 0.51$ & $5.95^{\mathrm{e}} \pm 0.66$ & $162.39^{\mathrm{b}} \pm 10.51$ & $454.47^{\mathrm{d}} \pm 25.36$ \\
\hline
\end{tabular}

*Without pre-gelatinization; ** Percentage of pre-gelatinization

Table 5. Sensory panel results for quinoa spaghetti trials (KitchenAid and extruder) and commercial spaghetti. Data are presented as means \pm standard deviations

\begin{tabular}{llllllllll}
\hline & Color intensity & Aggregated & Cereal & Herbaceous & Doughy & Firm & Breakable & Bitter & Global quality \\
\hline Control spaghetti * & $3.30^{\mathrm{a}} \pm 0.67$ & $2.70^{\mathrm{a}} \pm 1.16$ & $2.70^{\mathrm{a}} \pm 1.06$ & $3.30^{\mathrm{a}} \pm 1.06$ & $2.60^{\mathrm{a}} \pm 1.14$ & $2.80^{\mathrm{a}} \pm 1.03$ & $2.70^{\mathrm{ab}} \pm 1.06$ & $3.20^{\mathrm{a}} \pm 0.92$ & $2.78^{\mathrm{a}} \pm 0.67$ \\
$30 \% *$ & $3.30^{\mathrm{a}} \pm 1.16$ & $2.70^{\mathrm{a}} \pm 0.82$ & $2.80^{\mathrm{a}} \pm 0.92$ & $2.90^{\mathrm{ab}} \pm 1.20$ & $2.70^{\mathrm{a}} \pm 1.06$ & $2.50^{\mathrm{a}} \pm 0.85$ & $2.30^{\mathrm{ab}} \pm 0.67$ & $2.50^{\mathrm{bc}} \pm 0.97$ & $2.50^{\mathrm{a}} \pm 0.97$ \\
Extruder spaghetti & $3.10^{\mathrm{a}} \pm 0.99$ & $3.10^{\mathrm{a}} \pm 0.88$ & $3.10^{\mathrm{a}} \pm 1.10$ & $3.00^{\mathrm{ab}} \pm 0.82$ & $3.10^{\mathrm{a}} \pm 0.88$ & $2.60^{\mathrm{a}} \pm 0.97$ & $2.80^{\mathrm{a}} \pm 0.92$ & $2.70^{\mathrm{ab}} \pm 0.82$ & $2.50^{\mathrm{a}} \pm 1.08$ \\
Commercial spaghetti & $1.10^{\mathrm{b}} \pm 0.32$ & $2.30^{\mathrm{a}} \pm 1.34$ & $3.10^{\mathrm{a}} \pm 1.73$ & $2.00^{\mathrm{b}} \pm 1.05$ & $2.60^{\mathrm{a}} \pm 1.26$ & $2.90^{\mathrm{a}} \pm 1.20$ & $1.70^{\mathrm{b} \pm 0.95}$ & $1.70^{\mathrm{c}} \pm 0.67$ & $4.10^{\mathrm{b}} \pm 0.57$ \\
\hline
\end{tabular}

* Without pre-gelatinization; ** Percentage of pre-gelatinization

Table 6. Consumer panel results for quinoa spaghetti trials (KitchenAid and extruder) and commercial spaghetti. Data are presented as means \pm standard deviations

\begin{tabular}{lllll}
\hline & Appearance & Odor & Taste & Texture \\
\hline Control spaghetti $*$ & $2.70^{\mathrm{a}} \pm 1.16$ & $2.50^{\mathrm{a}} \pm 1.06$ & $2.50^{\mathrm{a}} \pm 1.18$ & $2.40^{\mathrm{a}} \pm 0.97$ \\
$30 \% * *$ & $2.50^{\mathrm{a}} \pm 1.08$ & $2.40^{\mathrm{a}} \pm 1.17$ & $2.60^{\mathrm{a}} \pm 0.97$ & $2.70^{\mathrm{a}} \pm 1.25$ \\
Extruder spaghetti & $2.30^{\mathrm{a}} \pm 1.16$ & $2.30^{\mathrm{a}} \pm 1.06$ & $2.50^{\mathrm{a}} \pm 1.18$ & $2.60^{\mathrm{a}} \pm 0.97$ \\
Commercial spaghetti & $4.20^{\mathrm{b}} \pm 1.23$ & $4.10^{\mathrm{b}} \pm 0.88$ & $4.10^{\mathrm{b}} \pm 0.74$ & $4.00^{\mathrm{b}} \pm 0.67$ \\
\hline
\end{tabular}

* Without pre-gelatinization; ** Percentage of pre-gelatinization

\section{Conclusions}

The goal of this study was to make quinoa pasta only with flour and water. The pre-gelatinization was used in order to improve the texture and the appearance of pasta because some other studies were successful with pre-gelatinization (Chillo et al., 2009; Mastromatteo et al., 2011). Indeed, with $38 \%$ of moisture content without pre-gelatinization, pasta were too breakable and sticky. It was difficult to make quinoa pasta with this moisture content thanks to KitchenAid whereas with pre-gelatinization quinoa pasta seemed good. Thus, pre-gelatinization improved appearance at the end of the KitchenAid but regarding results on physico-chemical properties, pre-gelatinization did not have expected impact. Indeed, pre-gelatinization had increased the percentage of cooking loss, the water activity and the percentage of water absorption. Moreover, the pre-gelatinization did not have an impact on moisture content, unit density, cooking time and the texture. Concerning the color, the pre-gelatinization had improved the lightness only for $30 \%$ of pre-gelatinization. The 
problem with the pre-gelatinization was probably due to an excessive starch swelling which caused damages, an irreversible disruption of the protein-starch network. Moreover, quinoa starch granules are smaller than wheat starch granules and there is a lower level of amylose in quinoa (Qian and Kuhn, 1999). Starch is a critical aspect. Starch plays an important role during the process. The effect of gelatinization during the pre-heated on starch depends on the cereal variety (Bustos et al., 2015). Moreover, researches carried out before with pre-gelatinization were not only with flour and water but they added others components like hydrocolloids or eggs in order to improve the protein-starch network (Larroza et al., 2015).

However, the pre-gelatinization needs to be put into perspective that even if results were not expected compared to commercial spaghetti, the results of the cooking loss, water activity and water absorption were not so bad. Concerning the consumer test, it is important to note that people do not eat pasta alone without butter or sauce. This fact could explain the lower score. Moreover, there is no universal pasta quality definition. Pasta quality is subjective opinion, which varies depending on the country in which they are consumed. The culture influences consumer's judgment (Guine and Correia, 2014).

The major problems with quinoa pasta was at the level of the texture, which was too breakable, with a lack of firmness, as well as the color of the quinoa pasta. But the commercial spaghetti were not manufacture in the same way, the processing conditions were not the same. Perhaps the texture of quinoa pasta could be improved with additional processing. The results using an extruder were bad but there were no temperature and only one screw speed level was tested. The continuing work should be focusing on the same moisture content used in this study on pre-gelatinized sample and on sample, which would be not pre-gelatinized, but with an extruder at several temperatures and several screw speed level in order to improve pasta quality. Furthermore, if it will not improve pasta quality, it would be interesting to add enzyme in order to reinforce the protein-starch network and pasta color.

\section{References}

Abugoch, L. E. (2009). Quinoa (Chenopodium quinoa Wild): Composition, Chemistry, Nutritional, and Functional Properties. Advances in Food and Nutrition Research, 58, 1-31. https://doi.org/10.1016/S1043-4526(09)58001-1

Agama, A. E., Islas, H. J. J., Osorio, D. P., Rendon, V. R., Utrilla, C. R. G., Angulo, O., \& Bello, P. L. A. (2009). Pasta With Unripe Banana Flour : Physical, Texture, and Preference Study. Journal of Food Science, 74, 263-267. https://doi.org/10.1111/j.1750-3841.2009.01215.x

Agence nationale de sécurité sanitaire de l'alimentation, de l'environnement et du travail (ANSES), (2013). Les proteins. Retrieved from https://www.anses.fr/fr/content/les-prot\%C3\%A9ines

American Association of Cereal Chemists (AACC). (2000). Method 44-19, Moisture-Air Oven Method, Drying at $135^{\circ}$ C. AACC Approved Methods. (10 ${ }^{\text {th }}$ ed.). St Paul, Minnesota.

American Association of Cereal Chemists (AACC). (2000). Method 66-50, Pasta and Noodle Cooking Quality-Firmness. AACC Approved Methods. St Paul, Minnesota.

Arendt, E. B., \& Dal Bello, F. (2009). The Science of Gluten-Free Foods and Beverages. Minnesota: American Association of Cereal Chemist. Chapter 4, Gluten-Free Cereal Products and Beverages, pp. 89-90. https://doi.org/10.1094/9781891127670

Atwell, B., \& Engleson, J. (2008). Gluten free Product Development. Quality Assurance \& Food Safety, 53(4), 180-184. https://doi.org/10.1094/CFW-53-4-0180

Bauer, W. J., Badoud, R., Loliger, J., \& Etournaud, A. (2010). Science et technologie des aliments. $1^{\mathrm{er}}$ ed. Presses Polytechniques et universitaires romandes : Lausanne. Chapter 4, Les glucides, pp. 247-267.

Belton, P. S., \& Taylor, J. R. N. (2002). Pseudocereals and Less Common Cereals. Germany: Springer-Verlag Berlin Heidelberg. Chapter 3, Quinoa, pp. 93-106. https://doi.org/10.1007/978-3-662-09544-7

Bustos, M. C., Perez, G. T., \& Leon, A. E. (2015). Structure and quality of pasta enriched with functional ingredients. The Royal Society of Chemistry, 5, 80-92. https://doi.org/10.1039/C4RA11857J

Chen, D., Inglett, G. E., \& Liu, S. X. (2015). Antioxidant Activities of Selective Gluten Free Ancient Grains. Food and Nutrition Sciences, 6, 612-621. https://doi.org/10.4236/fns.2015.67065

Chillo, S., Civica, V., Iannetti, M., Suriano, N., Mastromatteo, M., \& Del Nobile, M. A. (2009). Properties of quinoa and oat spaghetti loaded with carboxymethylcellulose sodium salt and pregelatinized starch as structuring agents. Carbohydrate Polymers, 78, 932-937. https://doi.org/10.1016/j.carbpol.2009.07.013 
Cunin, C., Handschin, S., \& Escher, F. (1995). Structural Changes of Starch during Cooking of Durum Wheat Pasta. Food Science and Technology, 28, 323-328. https://doi.org/10.1016/S0023-6438(95)94552-0

Delcour, J. A., Joye, I. J., Pareyt, B., Wilderjans, E., Brijs, K., \& Lagrain, B. (2012). Wheat Gluten Functionality as a Quality Determinant in Cereal-Based Food Products. Annual Review of Food Science and Technology, 3, 469-492. https://doi.org/10.1146/annurev-food-022811-101303

Feillet, P. (2000). Le grain de blé: composition et utilisation. INRA, Paris. Chapter 6, Biscuits, pâtes alimentaires et autres produits dérivés du blé, pp. 187-195.

Fiorda, F. A., Junior, M. S. S., Da Silvia, F. A., Fontinelle, S. L.R., \& Eiras, G. M. V. (2013). Amaranth flour, cassava starch and cassava bagasse in the production of gluten-free pasta: technological and sensory aspects. International Journal of Food Science and Technology, 48, 1977-1984. https://doi.org/10.1111/ijfs.12179

Food and Agriculture Organization of the United Nations (FAO). (2013). What is quinoa, Distribution and Production. Retrieved from http://www.fao.org/quinoa-2013/what-is-quinoa/distribution-and-production/en/

Food and Drug Administration (FDA). (2015). Gluten Free Now Means What It Says. Retrieved from http://www.fda.gov/ForConsumers/ConsumerUpdates/ucm363069.htm

Guine, R. P. F., \& Correia, P. M. R. (2014). Engineering Aspects of Cereal and Cereal-Based Product. CRC Press: Florida. Chapter 10, Pasta, pp. 211-238.

Hoseney, R. C. (1994). Principles of Cereal Science and Technology. $2^{\text {nd }}$ ed. Minnesota: American Association of Cereal Chemist. Chapter 15, Pasta and Noodles, pp.323-324.

Jancurova, M., Minarovicova, L., \& Dandár, A. (2009). Quinoa- A Review. Czech Journal of Food Sciences, 27(2), 71-79. https://doi.org/10.17221/32/2008-CJFS

Larrosa, V., Lorenzo, G., Zaritzky, N., \& Califano, A. (2015). Dynamic rheological analysis of gluten-free pasta as affected by composition and cooking time. Journal of Food Engineering, 160, 11-18. https://doi.org/10.1016/j.jfoodeng.2015.03.019

Mastromatteo, M., Chillo, S., Iannetti, M., Civica, V., \& Del Nobile, M. A. (2011). Formulation optimization of gluten-free functional spaghetti based on quinoa, maize and soy flours. International Journal of Food Science and Technology, 46, 1201-1208. https://doi.org/10.1111/j.1365-2621.2011.02613.x

Mirhosseini, H., Kazemi, M., Rashid, N. F. A., Amid, B. T., Cheong, K. W., \& Zulkurnain, M. (2015). Effect of partial replacement of corn flour with durian seed flour and pumpkin flour on cooking yield, texture properties, and sensory attributes of gluten free pasta. Food Science and Technology, 63, 184-190. https://doi.org/10.1016/j.lwt.2015.03.078

Mokrzycki, W. S., \& Tatol, M. (2011). Colour difference $\Delta$ E. Research Gate, 20(4), 383-411.

Ogungbenle, H. N. (2003). Nutritional evaluation and functional properties of quinoa (Chenopodium quinoa) flour. International Journal of Food Sciences and Nutrition, 54, 153-158. https://doi.org/10.1080/0963748031000084106

Padalino, L., Mastromatteo, M., Lecce, L., Cozzolino, F., \& Del Nobile, M. A. (2013). Manufacturing and characterization of gluten-free spaghetti enriched with vegetable flour. Journal of Cereal Science, 57, 33-342. https://doi.org/10.1016/j.jcs.2012.12.010

Qian, J. Y., \& Kuhn, M. (1999). Characterization of Amaranthus cruentus and Chenopodium quinoa Starch. Starch, 4, 116-120. https://doi.org/10.1002/(SICI)1521-379X(199904)51:4<116::AID-STAR116>3.0.CO;2-R

Raeker, M. O., Graines, C. S., Finney, P. L., \& Donelson, T. (1998). Granule Size Distribution and Chemical Composition of Starches from 12 Soft Wheat Cultivars. Cereal Chemistry, 75(5), 721-728. https://doi.org/10.1094/CCHEM.1998.75.5.721

Sanchez, K. A. (2012). Observations regarding consumption of Peruvian native grains (Quinoa, Amaranth and Kaniwa), weight status, and perceptions of potential risk factors, warning signs and symptoms of type 2 diabetes among Peruvians adults: a case study. Master of Science: University of Maryland.

Schoenlechner, R., Drausinger, J., Ottenschlaeger, V., Jurackova, K., \& Berghofer, E. (2010). Functional Properties of Gluten-Free Pasta Produced from Amaranth, Quinoa and Buckwheat. Plant Foods Human Nutrition, 65, 339-349. https://doi.org/10.1007/s11130-010-0194-0

Slavin, J. (2004). Whole grains and human health. Nutrition Research Reviews, 17, 99-110. 
https://doi.org/10.1079/NRR200374

Food and Agriculture Organization of the United Nations (FAO). (2015). World Food Situation. Retrieved from http://www.fao.org/worldfoodsituation/csdb/en/

Tudorica, C. M., Kuri, V., \& Brennan, C. S. (2002). Nutritional and Physicochemical Characteristics of Dietary Fiber Enriched Pasta. Journal of Agricultural and Food Chemistry, 50, 347-356. https://doi.org/10.1021/jf0106953

Union of Organizations of Manufacturers of Pasta Products of the European Union (UN.A.F.P.A), (2013). Pasta consumption in the European Union. Retrieved from http://www.pasta-unafpa.org/ingstatistics4.htm

\section{Copyrights}

Copyright for this article is retained by the author(s), with first publication rights granted to the journal.

This is an open-access article distributed under the terms and conditions of the Creative Commons Attribution license (http://creativecommons.org/licenses/by/4.0/). 